\title{
Photocatalytic Degradation of Methylene Blue Using Polymeric Membranes Based on Cellulose Acetate Impregnated with ZnO Nanostructures
}

\author{
Muna A. Abu-Dalo ${ }^{1, *(D)}$, Saja A. Al-Rosan ${ }^{2}$ and Borhan A. Albiss ${ }^{2, *(D)}$ \\ 1 Department of Chemistry, Faculty of Science and Arts, Jordan University of Science and Technology, \\ Irbid 22110, Jordan \\ 2 Nanomaterials Lab, Department of Physics, Faculty of Science and Arts, Jordan University of Science \\ and Technology, Irbid 22110, Jordan; sajaalrousan93@gmail.com \\ * Correspondence: maabudalo@just.edu.jo (M.A.A.-D.); baalbiss@just.edu.jo (B.A.A.)
}

Citation: Abu-Dalo, M.A.; Al-Rosan, S.A.; Albiss, B.A. Photocatalytic Degradation of Methylene Blue Using Polymeric Membranes Based on Cellulose Acetate Impregnated with ZnO Nanostructures. Polymers 2021, 13, 3451. https://doi.org/10.3390/ polym 13193451

Academic Editor: Dalius Jucius

Received: 31 August 2021

Accepted: 4 October 2021

Published: 8 October 2021

Publisher's Note: MDPI stays neutral with regard to jurisdictional claims in published maps and institutional affiliations.

Copyright: (c) 2021 by the authors. Licensee MDPI, Basel, Switzerland. This article is an open access article distributed under the terms and conditions of the Creative Commons Attribution (CC BY) license (https:/ / creativecommons.org/licenses/by/ $4.0 /)$.

\begin{abstract}
This paper studied the photocatalytic degradation of methylene blue (MB) using polymeric membrane impregnated with $\mathrm{ZnO}$ nanostructures under UV-light and sunlight irradiation. ZnO nanoparticles and $\mathrm{ZnO}$ nanowires were prepared using the hydrothermal technique. Cellulose acetate polymeric membranes were fabricated by the phase inversion method using dimethylformamide (DMF) as a solvent and $\mathrm{ZnO}$ nanostructures. The structural properties of the nanostructures and the membranes were investigated using XRD, SEM, FTIR, and TGA measurements. The membranes were tested for photocatalytic degradation of MB using a UV lamp and a sunlight simulator. The photocatalytic results under sunlight irradiation in the presence of cellulose acetate impregnated with $\mathrm{ZnO}$ nanoparticles (CA-ZnO-NP) showed a more rapid degradation of $\mathrm{MB}$ (about 75\%) compared to the results obtained under UV-light irradiation degradation (about 30\%). The results show that CA-ZnO-NP possesses the photocatalytic ability to degrade MB efficiently at different levels under UV-light and sunlight irradiation. Modified membranes with $\mathrm{ZnO}$ nanoparticles and $\mathrm{ZnO}$ nanowires were found to be chemically stable, recyclable, and reproducible. The addition of $\mathrm{ZnO}$ nanostructure to the cellulose membranes generally enhanced their photocatalytic activity toward $\mathrm{MB}$, making these potential membranes candidates for removing organic pollutants from aqueous solutions.
\end{abstract}

Keywords: photocatalytic activity; polymeric membrane; methylene blue; $\mathrm{ZnO}$ nanostructures

\section{Introduction}

Water is a valuable natural resource, and its quality and availability are essential for the survival of the earth's living creatures. Industrial wastewater is one of the most significant sources of organic water pollutants during the last century due to excessive discharge into various natural water resources. In the last few years, parallel to the accelerated development of dye industries; this behavior has resulted in a serious water problem and caused negative effects on the environment and human lives. Methylene blue (MB) is a well known organic dye that forms a stable solution with water at room temperature [1]. MB is reported to be quite harmful when it exceeds specific concentrations, due to its high toxicity. Furthermore, most organic dyes do not biodegrade easily because they are highly resistant to environmental conditions, making their removal from wastewater both a critical need and a challenging task [2]. In this regard, it is essential to develop effective, low-cost, and novel materials for $\mathrm{MB}$ and other organic dye removal from aqueous solutions to bring life back to the environment.

Several methods have been used for removing dyes from aqueous solutions, including physical, chemical, and biological ones. These processes vary in their effectiveness, cost, and environmental impacts. Among these methods, high-efficiency aproaches such as adsorption [3], oxidation [4], Fenton ozonation [5], and photocatalytic degradation [6,7] are considered promising technologies for treating organic pollutants. 
Membranes Technology is widely used to solve crucial energy and environmental problems and is often employed for water purification. For such purification processes, there is a strong need for membranes with the ability to control the transport of small molecules (such as water) or ions. In this regard, polymeric materials have an important role in membrane research and development due to their unique processability, low cost, availability, energy efficiency, simple fabrication at various scales, and minimal use of harmful and toxic chemicals. Polymeric membrane technology has also been used to treat wastewater containing organic pollutants. The integration between the membrane separation process and photocatalysts is a point of great interest.

Cellulose - one of the most abundant biopolymers, generally used as a reinforcing material for fiber technology-is known to be an inexhaustible resource for sustainable natural polymers, in the presence of the growing demand for producing biodegradable and eco-friendly materials [8-13]. Moreover, cellulose-based materials have many advantages, such as being environmentally friendly, biocompatible, and cost-effective sources of carbon-based polymers and substrates for developing nanocomposites with novel material properties. One of the most common cellulose derivatives, cellulose acetate (CA), has many unique properties, such as nontoxicity, renewability, cost-effectiveness, and biodegradability. CA is also a widely used polymer for wastewater treatment membranes. The CA membrane usually consists of only one polymeric material and contains an asymmetric structure with a very thin and dense solute used to reject the active layer on a coarse supporting layer [13-16].

The application of nanocomposite (hybrid) materials as catalysts or adsorbents to remove toxic substances from wastewater has received great attention in the last decade. The adsorbents may be of mineral, organic, or biological origin, such as clay, zeolites, activated carbons, silica beads, polymeric materials, and metal oxides [17-22].

Among metal oxides, zinc oxide $(\mathrm{ZnO})$ in its nanostructured form is a favorable semiconducting oxide for application as a nanocomposite polymeric material due to its large variety of low dimensional nanostructures, effective adsorption, high surface reactivity, adsorption capacity, and destructive sorbent ion capacity [14-23]. ZnO nanostructures (such as nanoparticles, nanowires, nanoflowers, and nanosheets) as multifunctional inorganic nanomaterials have been widely applied in the polymeric membrane modification process [24-28]. However, there are still challenging issues regarding the stability, biocompatibility, and efficiency of these membranes when used in real-life filtration or treatment units. The produced polymer/nanocomposite materials should exhibit superior electrical, mechanical, thermal, and chemical properties; good permeability; thermal stability; microbial resistance; and excellent water selectivity [29-33].

Many studies have been done on nanocomposite membranes in wastewater treatment. For example, Zhao et al. [34] improved the permeability and anti-fouling performance of polyethersulfone ultrafiltration membrane by incorporation of ZnO-DMF dispersion containing nano- $\mathrm{ZnO}$ and polyvinylpyrrolidone. The results indicated that the incorporated nano- $\mathrm{ZnO}$ was favorable and enhanced compaction resistance and anti-fouling properties by reducing the irreversible fouling resistance of membranes. The inclusion of nano- $\mathrm{ZnO}$ also led to thermal stability improvements below $450{ }^{\circ} \mathrm{C}$ of the membranes. In another study by Feiya Fu and Lingyan Li [35], cellulose-based $\mathrm{ZnO}$ nanocomposite was prepared through one-step coagulation; $\mathrm{ZnO}$ nanoparticles were agglomerated into large clusters embedded in the cellulose matrix. The nanocomposite showed good mechanical properties, high thermal stability, excellent UV-blocking properties, and antibacterial activity. Furthermore, Cheng et al. [36] reported a new deacetylated cellulose acetate polydopamine composite nanofiber membrane fabricated by electrospinning and surface modification. The membrane was applied as a highly efficient adsorbent for removing MB from an aqueous solution. The composite nanofibers were employed as highly efficient adsorbents for removing $\mathrm{MB}$ from an aqueous solution. In our recent study [37], we reported the fabrication of activated carbon fiber (ACF)/ZnO nanorod (NR) nanocomposite with unique microstructural and photocatalytic properties; the adsorption and photocatalytic activity 
of the synthesized catalytic adsorbents were compared using MB under UV-light irradiation. The nanocomposite showed excellent photocatalytic activity ( $99 \%$ degradation of $\mathrm{MB}$ in $2 \mathrm{~h}$ ) compared with bare $\mathrm{ZnO}-\mathrm{NR}$ and ACF. Additionally, a recycling experiment demonstrated the stability of the photocatalyst. The enhanced photocatalytic activity may be related to the synergetic adsorption-photocatalytic degradation effect of ACF and $\mathrm{ZnO}$ nanostructures.

The present study describes the development of a new polymeric membrane based on $\mathrm{CA}-\mathrm{ZnO}$ nanocomposite. $\mathrm{ZnO}$ nanostructures were impregnated or grown in the cellulose acetate polymer matrix using simple and cost-effective sonication and hydrothermal processes in this nanocomposite. The pristine CA, CA-ZnO-NP, and CA-ZnO-NW membranes were prepared and characterized, and their photocatalytic activity toward $\mathrm{MB}$ in aqueous solutions were investigated using a UV lamp and a sunlight simulator. The membranes were characterized using XRD, SEM, FT-IR, TGA, UV-vis, and contact angle tests. A membrane separation process coupled with photocatalysts can act as a barrier for MB dye to enhance the photocatalytic degradation and treatment process of wastewater.

\section{Materials and Methods}

\subsection{Materials}

Zinc nitrate, zinc acetate, ammonium carbonate, $\mathrm{NaOH}$, and ethanol obtained from Sigma Aldrich Chemical Co, St. Louis, MO, USA, were used to prepare $\mathrm{ZnO}$ nanoparticles and $\mathrm{ZnO}$ nanowires. Hexamethylenetetramine (HMTA) and cellulose acetate and dimethylformamide (DMF) were obtained from Sigma Aldrich Chemical Co, USA, to prepare the membrane casting solution.

\subsection{Synthesis of $\mathrm{ZnO}$ Nanoparticles}

$\mathrm{ZnO}$ nanoparticles were prepared by hydrothermal method. An equimolar solution of $0.5 \mathrm{M}$ of zinc nitrate $\mathrm{Zn}\left(\mathrm{NO}_{3}\right)_{2}$ and ammonium carbonate $\left(\mathrm{NH}_{4}\right)_{2} \mathrm{CO}_{3}$ was dissolved and stirred separately in deionized water at room temperature. The precursor was prepared by adding $\mathrm{Zn}\left(\mathrm{NO}_{3}\right)_{2}$ solution dropwise into the vigorously stirred $\left(\mathrm{NH}_{4}\right)_{2} \mathrm{CO}_{3}$ with a molar ratio of 1:1.5, forming white precipitates. These precipitates were collected by filtration and repeatedly rinsed with deionized water. The rinsed precipitates were dried at $90^{\circ} \mathrm{C}$ for $6 \mathrm{~h}$ to form the final $\mathrm{ZnO}-\mathrm{NPs}$.

\subsection{Synthesis of $\mathrm{ZnO}$ Nanowires}

\subsubsection{Preparation of $\mathrm{ZnO}$ Seed Solution}

To obtain $\mathrm{ZnO}$ nanoparticle seeds, two solutions were prepared: $1 \mathrm{mM}$ of zinc acetate in $100 \mathrm{~mL}$ ethanol and $1 \mathrm{mM}$ of $\mathrm{NaOH}$ in $20 \mathrm{~mL}$ ethanol, which were stirred with heating at $50{ }^{\circ} \mathrm{C}$. $\mathrm{NaOH}$ solution was added to the zinc acetate solution dropwise while stirring. Then, the mixed solutions were heated in the water bath for $1 \mathrm{~h}$ at $60^{\circ} \mathrm{C}$.

\subsubsection{Growth Solution Preparation}

For the growth of $\mathrm{ZnO}$ nanoparticles, $1 \mathrm{mM}$ Hexamethylenetetramine (HMTA) in $100 \mathrm{~mL}$ ethanol and zinc nitrate in $100 \mathrm{~mL}$ ethanol were prepared and mixed with stirring.

\subsubsection{Growth of $\mathrm{ZnO}$ Nanowires}

A few drops of the seed solution were added onto the glass substrate by spin coater to make a layer, and then it was dried on a hot plate at $40^{\circ} \mathrm{C}$. This step was repeated three times. Then, the substrate was placed in the growth solution with the seed layer facing the bottom to form the nanowires. The growth solution with the substrate was placed in a water bath at $90{ }^{\circ} \mathrm{C}$ for $2 \mathrm{~h}$. After that, the substrate was dried at room temperature. $\mathrm{ZnO}$ nanowires were scraped (white layer) from the top of the substrate. 


\subsection{Membrane Preparation}

To obtain the optimum $\mathrm{ZnO}$ concentrations in the $\mathrm{CA}$ matrix, several experiments were done for $\mathrm{ZnO}$ content $(0.1 \%, 0.5 \%, 1 \%$, and $5 \% \mathrm{wt} \%)$. The best membrane performance obtained was with $\mathrm{ZnO}(5 \%)$. A control cellulose acetate polymeric membrane was prepared using the phase inversion method, in which $15 \%$ weight cellulose acetate was dissolved in $85 \%$ dimethylformamide (DMF) under constant mechanical stirring for $1-2 \mathrm{~h}$ at $40{ }^{\circ} \mathrm{C}$. The obtained homogeneous solution was allowed to stand in the air to remove the air bubbles. The cellulose acetate impregnated with $\mathrm{ZnO}$ nanoparticles was prepared similarly, except that $5 \% \mathrm{ZnO}$ nanoparticles were added to the membrane solution.

All membranes were prepared by casting using a spin coater at a speed of $1000 \mathrm{rpm}$ for $10 \mathrm{~s}$ using the model "Laurell WS- 650-23", Laurell Technologies Corporation, North Wales, PA, USA.

\subsection{Membrane Casting}

CA membrane casting using the $C A \backslash D M F$ solution on a mirror was performed using spin-coating techniques. After casting, the mirror was immersed in a deionized water bath for 3-4 min until the membrane separated from the mirror. An optical sample image of the prepared membranes is shown in Figure 1.

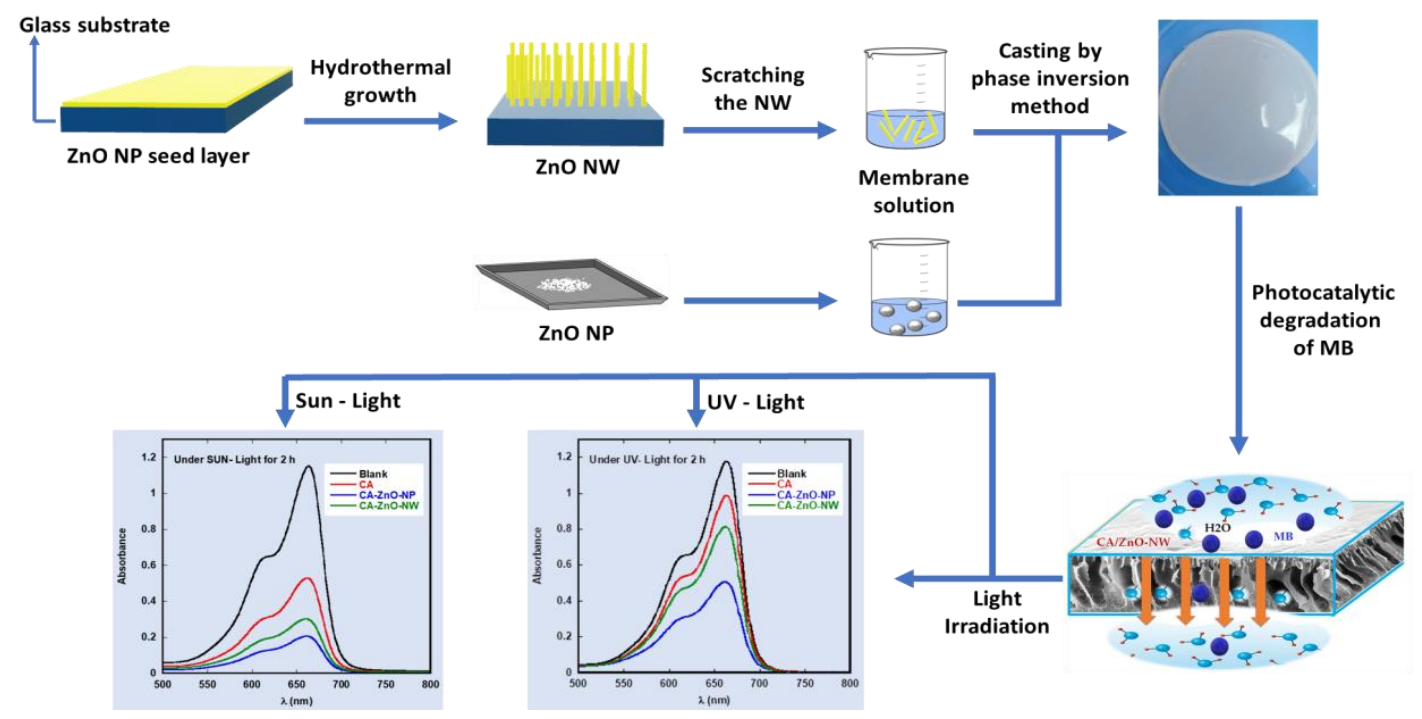

Figure 1. Schematic illustration of CA-ZnO-nanostructured membrane preparation and testing processes.

\subsection{Photocatalytic Activity Evaluation}

The photocatalytic activity of all prepared CA-ZnO nanocomposites with various $\mathrm{ZnO}$ nanostructures was evaluated with respect to $\mathrm{MB}$ photocatalytic degradation. Then, the nanocomposite with the best photocatalytic activity and performance was subjected to a detailed study. The photocatalytic activity of the prepared photocatalysts (pristine $\mathrm{CA}, \mathrm{CA}-\mathrm{ZnO}-\mathrm{NP}, \mathrm{CA}-\mathrm{ZnO}-\mathrm{NW}$ ) were evaluated by observing the degradation of (MB) pollutants. MB stock solution was prepared by dissolving it in distilled water at $100 \mathrm{mg} \mathrm{L}^{-1}$ into a $250 \mathrm{~mL}$ beaker. Then, $10 \mathrm{mg}$ of CA, CA-ZnO-NP, and CA-ZnO-NW photocatalysts (each in a separate $10 \mathrm{~mL}$ bottle) were added to the $\mathrm{MB}$ solution at a $\mathrm{pH}$ of 7 . To ensure adsorption/desorption equilibrium of $\mathrm{MB}$ on these photocatalysts, the solutions were mixed using a magnetic stirrer in dark medium for $30 \mathrm{~min}$ and centrifuged at $3000 \mathrm{rpm}$ for $5 \mathrm{~min}$. The UV-vis absorption spectrum of the solution was measured in the range of 200-800 $\mathrm{nm}$. Then, the mixture was exposed to a UV lamp ( 6 Watts, $\lambda=365 \mathrm{~nm}$ ). The initial $\mathrm{MB}$ concentration was $50 \mathrm{mg} \mathrm{L}^{-1}$ and the temperature of the reaction solution was maintained at $30.0 \pm 0.5{ }^{\circ} \mathrm{C}$. Ten samples were taken with fixed time intervals of 10 and 20 min after UV radiation, and their absorption spectrum was recorded. The residual 
concentration of MB dye in the solution was measured to have a major peak at $664 \mathrm{~nm}$ using a UV-visible spectrophotometer.

The same procedure was applied for sunlight irradiation using a sunlight simulator (Peccell's sunlight simulator, PEC-L15, Peccell Technologies, Inc., Yokohama, Japan) with a sunlight irradiance of $100 \mathrm{~mW} / \mathrm{cm}^{2}$.

A blank sample (containing no dye) was used as a control, and a calibration curve of absorbance versus concentration was constructed. Samples were collected at $15 \mathrm{~min}$ time intervals (up to $2 \mathrm{~h}$ ) and centrifuged to remove the catalyst before analysis. The degradation efficiency of the MB was calculated by Equation (1).

$$
\% \text { Degradation }=\left(C_{0}-C_{t}\right) \times 100 / C_{0}
$$

where $\mathrm{C}_{0}=$ initial $\mathrm{MB}$ concentration and $\mathrm{Ct}=\mathrm{MB}$ concentration after time $\mathrm{t}$.

To detect MB degradation products in the presence of CA-ZnO-NP membranes, total organic carbon (TOC), ammonium, nitrate, and sulfate concentrations were determined in the presence and absence of CA-ZnO-NP membranes under UV-light and sunlight irradiation using Lovibond kits and methods: TOC-1K and TOC-2K method 381, AMMONIA No.1 and AMMONIA No.2 method 60, VARIO Nitrate Chromotropic method 265, and Vario sulfa 4 method 355, respectively. All tests were analyzed using a spectrophotometer (Lovibond SpectroDirect, Dortmund, Germany) at 330-900 nm. Zn concentrations for leaching tests were analyzed quantitatively using atomic absorption flame emission spectroscopy ( Shimadzu (AA-6200), Shimadzu Co., Kyoto, Japan).

\section{Results}

\subsection{X-ray Diffraction (XRD)}

$\mathrm{X}$-ray diffraction spectra for the samples have been obtained using $\mathrm{Cu}-\mathrm{K} \alpha$ radiation $(\lambda=1.542 \AA)$. Figure 2 shows the $X$-ray diffraction spectra for $\mathrm{ZnO}-\mathrm{NP}, \mathrm{ZnO}-\mathrm{NW}, \mathrm{CA}, \mathrm{CA}-$ ZnO-NP, and CA-ZnO-NW. The CA-ZnO-NP membrane, CA-ZnO-NW membrane, and $\mathrm{ZnO}-\mathrm{NP}$ samples displayed typical major diffraction peaks at $2 \theta=31.60^{\circ}, 34.24^{\circ}, 36.17^{\circ}$, $47.38^{\circ}$, and $56.32^{\circ}$, which were ascribed to the (100), (002), (101), (102), and (110) planes of the $\mathrm{ZnO}$ crystal structure form, respectively [38]. The CA membrane, CA-ZnO-NP membrane, and CA-ZnO-NW membrane showed broad peaks at $2 \theta=23.30^{\circ}, 27.23^{\circ}, 18.17^{\circ}$, respectively, confirming the presence of cellulose acetate matrix [39].

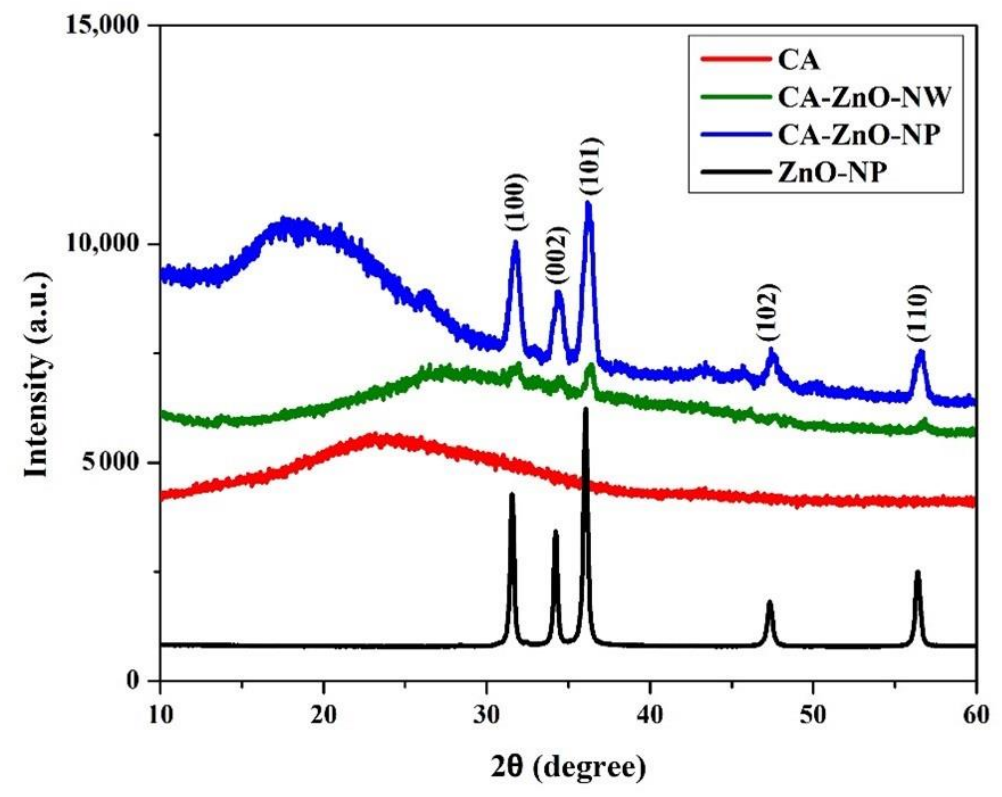

Figure 2. XRD patterns of the pristine $\mathrm{CA}, \mathrm{CA}-\mathrm{ZnO}-\mathrm{NP}$, and $\mathrm{CA}-\mathrm{ZnO}-\mathrm{NW}$ membranes. 
The growth of nanowires was in random orientations, which may be the reason for the presence of peaks with relatively low intensities and crystallinity for the CA-ZnO-NW nanostructure compared to those for the CA-ZnO-NP ones. However, samples with CA content exhibited an amorphous nature in the Brag's angle $(2 \theta)$ range between $10^{\circ}$ and $30^{\circ}$.

An XRD analysis of the spent photocatalysts was performed after 3 days of photocatalytic experimentation. The preliminary results of the XRD pattern comparison between the pristine and the spent catalyst revealed that the patterns were remarkably similar. No changes in either XRD peak intensities or in the inter-planar spacing were observed after 3 days of the photocatalytic experimentation. This indicates that the spent photocatalysts had chemical and morphological stability.

Figure 3 shows the SEM morphologies of the pristine CA, CA-ZnO-NP, and CA-ZnO$\mathrm{NW}$ membranes. In a typical membrane, the water and ion permeability is determined by the active layer on the top surface, while the structural parameters influence the microstructure of the porous support layer. In phase inversion membranes, void microstructures are usually divided into two cases: a sponge-like structure and finger-like macro-voids. The pristine CA membrane (Figure 3a) showed a uniform and dense top surface with a few randomly scattered grains, which may be attributed to some impurities present during the fabrication process. However, the top surface of the CA-ZnO-NP and CA-ZnONW (Figure 3d,g) were less dense, and the assembled nanostructures (nanoparticles and nanowires) were well distributed and dispersed over the whole surfaces and impregnated with the CA-polymer matrix. Moreover, a few pores of various sizes (less than $1 \mu \mathrm{m}$ ) could be easily seen in all membranes. Micrographs of the membranes' bottom layers are presented in Figure 3b,e,h. The bottom layer of the pristine CA membrane demonstrated a highly porous layer with a well ordered micro-network. However, the ZnO-NP and $\mathrm{ZnO}-\mathrm{NW}$ nanostructures were incorporated in the bottom surface of the membranes (Figure 3e,h) as an agglomeration of $\mathrm{ZnO}$ nanostructures with various sizes and shapes (nanowires, nanoparticles, nanoflowers). These incorporated particles in the active layer improve water permeability by providing alternative flow paths to water molecules. In this regard, choosing the optimum concentrations of the $\mathrm{ZnO}$ nanostructures is crucial in membrane fabrication, since larger nanostructure agglomerations can cause a structural defect in the membrane. The $\mathrm{ZnO}$ nanostructures had obvious clustering/agglomeration visible on the top layer and in the cross section of membranes (Figure $3 \mathrm{e}, \mathrm{f}, \mathrm{h}, \mathrm{i}$ ). However, serious agglomeration for higher concentrations may lead to pore plugging, which may negatively affect the membrane performance. For the pristine CA membrane, cross-sectional SEM images (Figure 3c,f,i) showed that a sponge-like structure occupied most of the support layer, and only a few finger-like macro-voids were present. However, longer vertical fingers with numerous shapes were formed in the $\mathrm{CA}-\mathrm{ZnO}$ nanocomposite membrane support layers. The growth of the $\mathrm{ZnO}$ nanostructures can easily be seen in the cross-sectional images of the CA-ZnO-NP and CA-ZnO-NW membranes (Figure 3f,i).

\subsection{Fourier-Transform Infrared Spectroscopy (FTIR)}

Figure 4 shows the FTIR spectra for the $\mathrm{ZnO}-\mathrm{NP}, \mathrm{ZnO}-\mathrm{NW}, \mathrm{CA}, \mathrm{CA}-\mathrm{ZnO}-\mathrm{NP}$, and CA-ZnO-NW membranes. The infrared absorption spectra of the samples were observed in the 400-4000 $\mathrm{cm}^{-1}$ wavenumber range. For all membranes, the broad peaks at $607 \mathrm{~cm}^{-1}$ were assigned to the aromatic $\mathrm{C}-\mathrm{OH}$ bond polymer chain. The peak of $\mathrm{C}-\mathrm{O}$ stretching was present at $1029 \mathrm{~cm}^{-1} . \mathrm{C}=\mathrm{O}$ exhibited a strong asymmetric mode of vibration at $1733 \mathrm{~cm}^{-1}$. A small peak at $2958 \mathrm{~cm}^{-1}$ is due to the stretching of the C-O group of cellulose. Moreover, the peak at $3396 \mathrm{~cm}^{-1}$ endorses the $\mathrm{O}-\mathrm{H}$ bond of the membranes. For the $\mathrm{ZnO}-\mathrm{NP}$ and $\mathrm{ZnO}-\mathrm{NW}$ samples, the presence of absorption bands at 417 and $461 \mathrm{~cm}^{-1}$ are due to $\mathrm{Zn}-\mathrm{O}$ bond stretching in the $\mathrm{ZnO}$ structure. The $\mathrm{C}=\mathrm{O}$ peak is at $1593 \mathrm{~cm}^{-1}$ in the $\mathrm{ZnO}-\mathrm{NP}$ sample and $1630 \mathrm{~cm}^{-1}$ in the $\mathrm{ZnO}-\mathrm{NW}$ sample. In the CA-ZnO-NP and CA-ZnO-NW samples, the $\mathrm{Zn}-\mathrm{O}$ peaks were present at $428 \mathrm{~cm}^{-1}$ and $401 \mathrm{~cm}^{-1}$, respectively. 


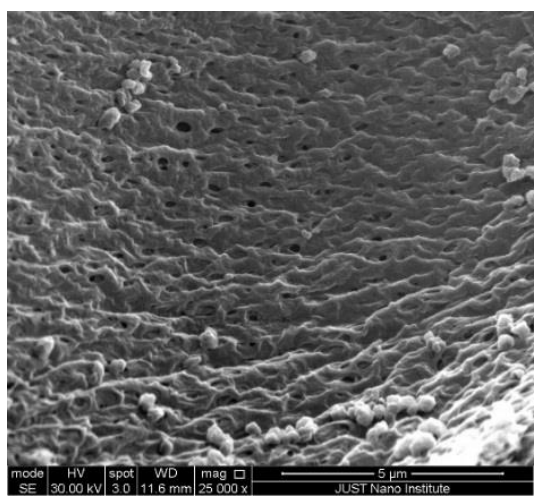

(a)

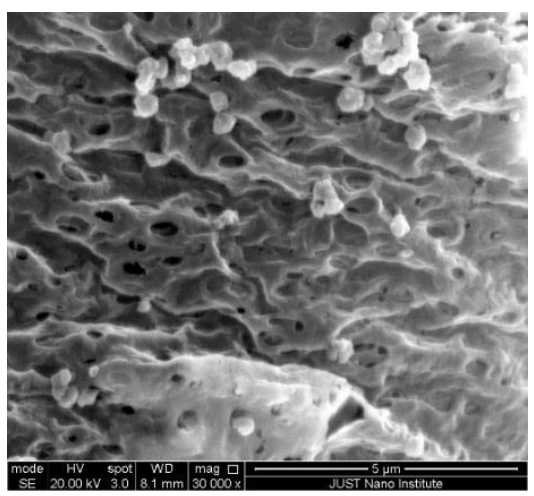

(d)

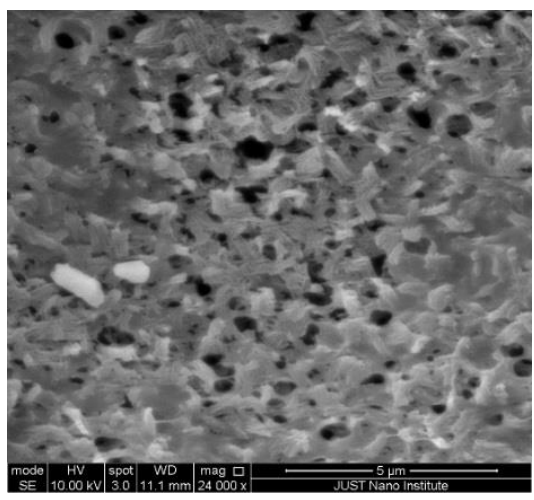

(g)

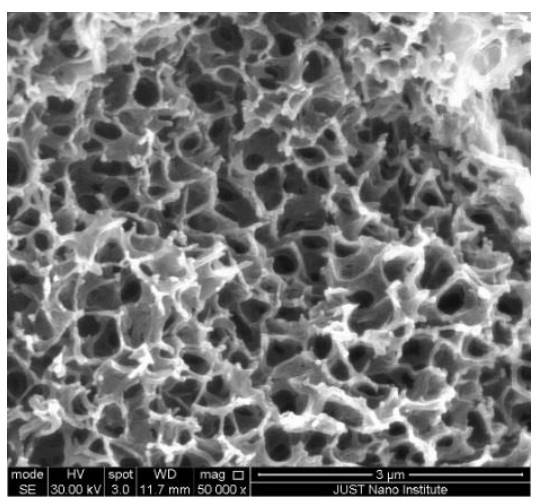

(b)

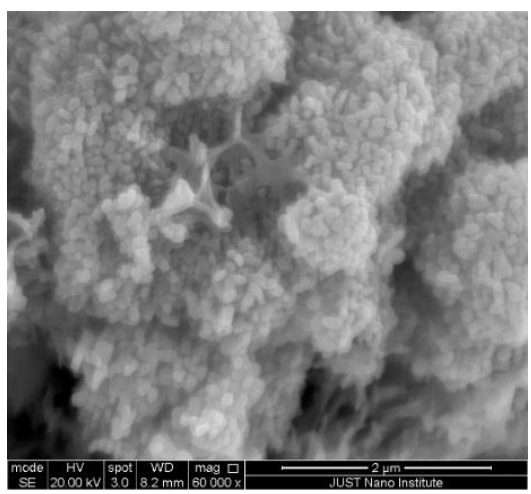

(e)

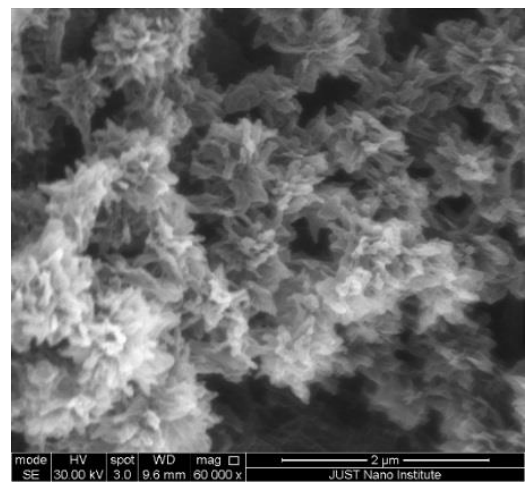

(h)

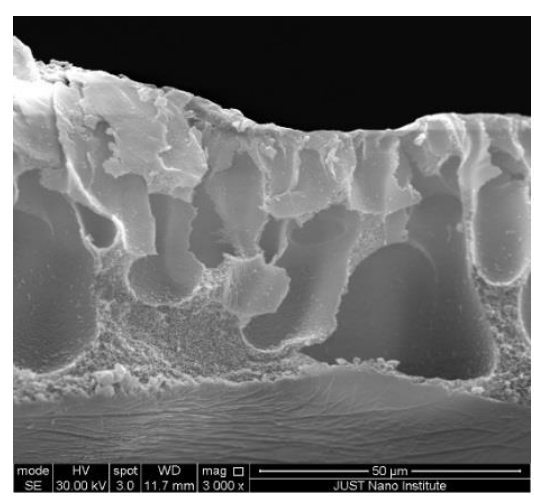

(c)

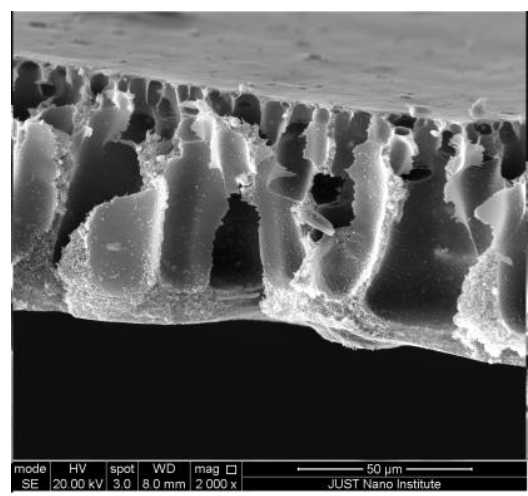

(f)

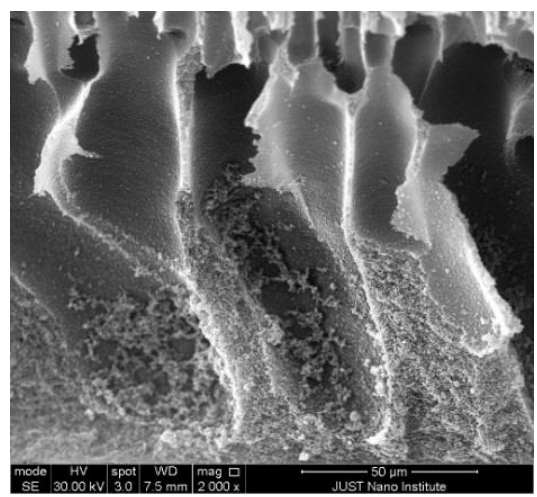

(i)

Figure 3. SEM morphologies of the pristine CA membrane $(\mathbf{a}-\mathbf{c})$, the CA-ZnO-NP membrane (d-f), and the CA-ZnO-NW membrane ( $\mathrm{g}-\mathbf{i})$. Images on the left, middle, and right correspond to the top surface, bottom surface, and cross-sectional images of the membranes, respectively.

\subsection{Thermogravimetric Analysis (TGA)}

TGA curves of CA, CA-ZnO-NP, and CA-ZnO-NW membranes are illustrated in Figure 5. Generally, there were three steps of degradation in the TGA curve for all membranes. The first step started from $52{ }^{\circ} \mathrm{C}$ to $201{ }^{\circ} \mathrm{C}$ for the CA membrane and from $33{ }^{\circ} \mathrm{C}$ to $73{ }^{\circ} \mathrm{C}$ with $74.34 \%$ mass change for the CA-ZnO-NP membrane and $69.63 \%$ mass change for the CA-ZnO-NW membrane. This weight loss for prepared membranes can be ascribed to evaporation of remaining solvents, the evaporation of residual absorbed water, and easily volatile products of membrane thermal degradation. In the second step, there was a sharp weight drop from $287^{\circ} \mathrm{C}$ to $400{ }^{\circ} \mathrm{C}$ with $88.76 \%$ mass change for the CA membrane, from $302{ }^{\circ} \mathrm{C}$ to $397^{\circ} \mathrm{C}$ with a mass change of $19.30 \%$ for the $\mathrm{CA}-\mathrm{ZnO}-\mathrm{NP}$ membrane, and from $302{ }^{\circ} \mathrm{C}$ to $387^{\circ} \mathrm{C}$ with a mass change of $25.35 \%$ for the $\mathrm{CA}-\mathrm{ZnO}-\mathrm{NW}$ membrane. The second step represents the main thermal degradation of the cellulose acetate chains. The 
last step for all membranes started at $433{ }^{\circ} \mathrm{C}, 410{ }^{\circ} \mathrm{C}$, and $402{ }^{\circ} \mathrm{C}$ for the CA, CA-ZnO-NP, and $\mathrm{CA}-\mathrm{ZnO}-\mathrm{NW}$ membranes, respectively, indicating the carbonization of the degraded products to ash. These three steps may correspond to steps suggested by [40].

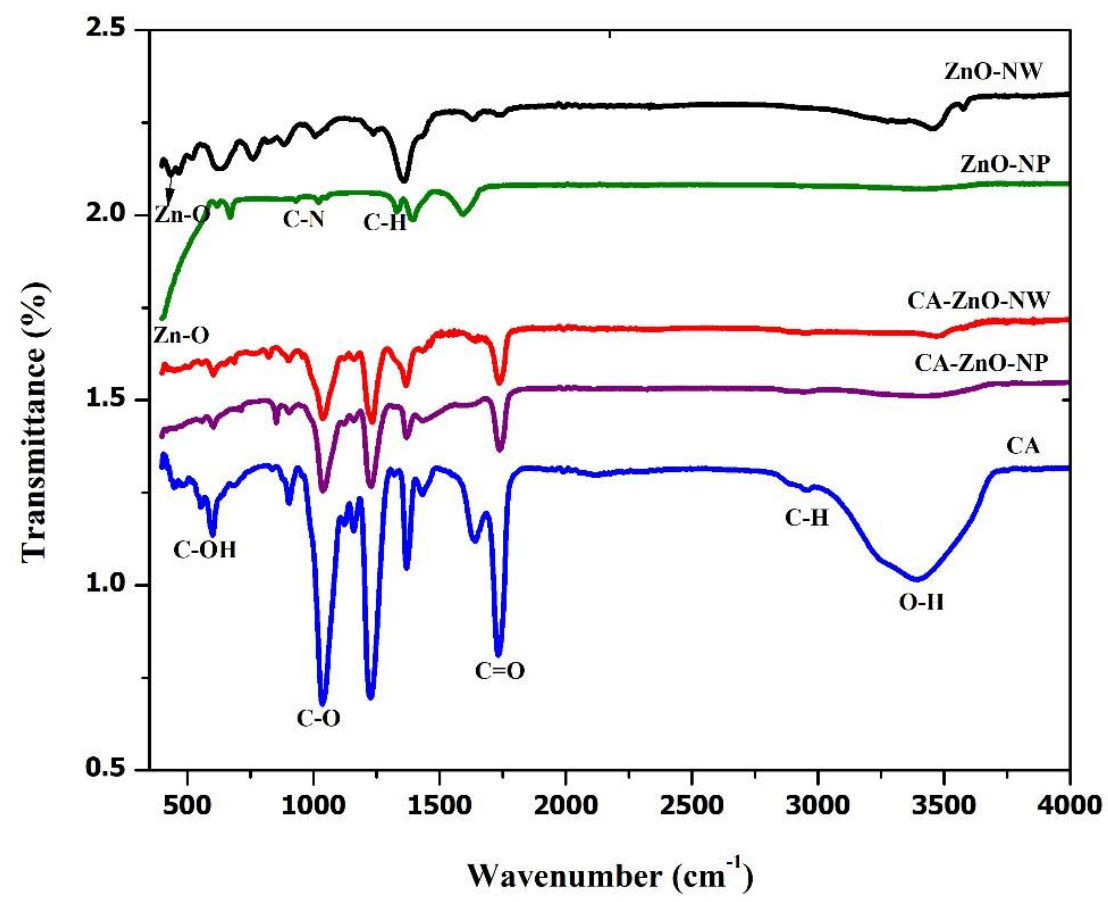

Figure 4. FTIR spectra of the pristine CA membrane, the CA-ZnO-NP membrane, and the CA-ZnONW membrane.

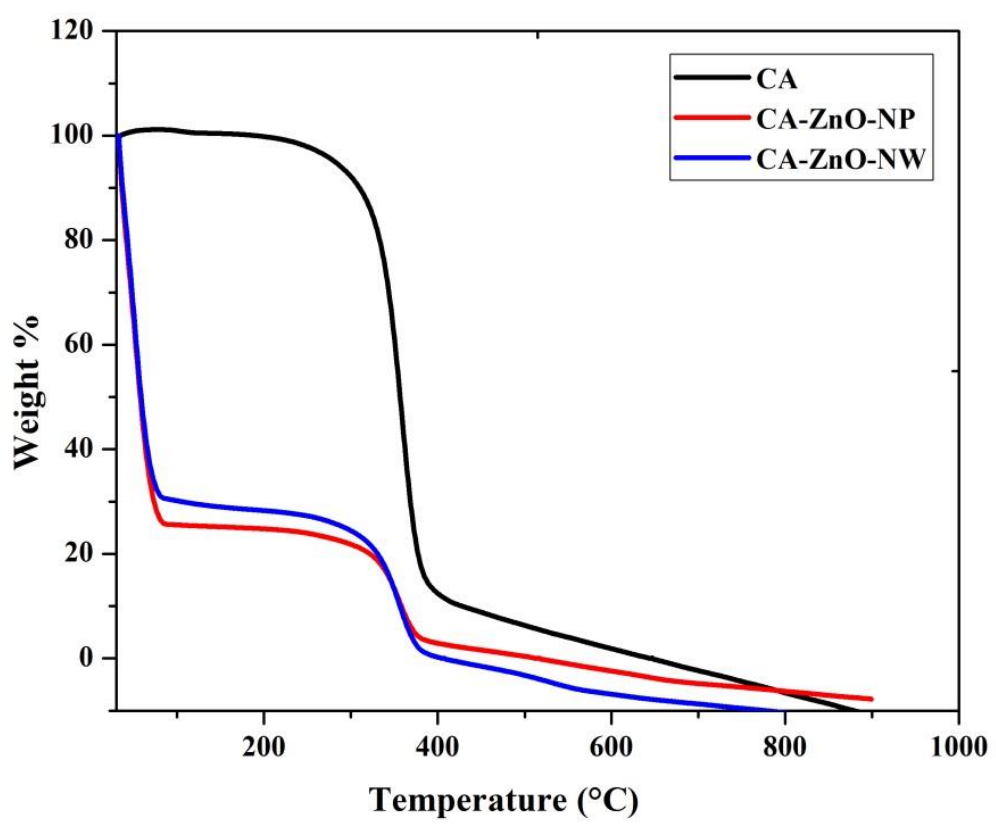

Figure 5. TGA data of the pristine CA membrane, the CA-ZnO-NP membrane, and the CA-ZnONW membrane.

\subsection{Water Contact Angle Measurement}

The contact angle tests for the membranes were conducted using an experimental setup developed at our lab. An apparatus that is quite efficient, precise, and low cost was used for static contact angle measurements, which proved to be adequate for measuring 
contact angles of a $\sim 10 \mu \mathrm{L}$ DI water droplet injected from an automated syringe dispenser. The droplet image was taken using "Stereomicroscopes SZO-8, Optika, Ponteranica (BG), Italy" Stereo zoom microscope equipped with a digital camera. The profile of the drop was processed with ImageJ free source software (V 1.8.0_172). The drop-shape analysis was based on a sessile drop technique by placing a water drop on a dry membrane surface exposed to the surrounding air and measuring the contact angle that the drop makes with the membrane surface. Since the static water contact angle may change with time for various reasons, a snapshot picture of the drop with the membrane surface was taken during the first few seconds after dropping, through which the contact angle was almost constant. The ratio of the cohesive forces to adhesive forces between the water droplet and the membrane surface provides an indication of the size of the contact angle. Reported contact angle data was obtained by averaging three points on each surface. For each membrane, two different surfaces were tested.

Figure 6 shows the contact angle measurement of the pristine CA membrane, the CA-ZnO-NP membrane and the CA-ZnO-NW membrane. The insets show a photograph of a water droplet on each membrane. A gradual decrease in the contact angle was observed for CA-ZnO-NP $\left(49.07^{\circ} \pm 1.22^{\circ}\right)$ and CA-ZnO-NW $\left(38.09^{\circ} \pm 0.95^{\circ}\right)$, compared to pristine CA $\left(63.86^{\circ} \pm 1.60^{\circ}\right)$. A consistent suppression in the contact angle with the addition of $\mathrm{ZnO}-\mathrm{NP}$ and $\mathrm{ZnO}-\mathrm{NW}$ proved that the addition of hydrophilic $\mathrm{ZnO}$ nanostructures on the surface of the CA membrane improves the hydrophilicity of the membrane.

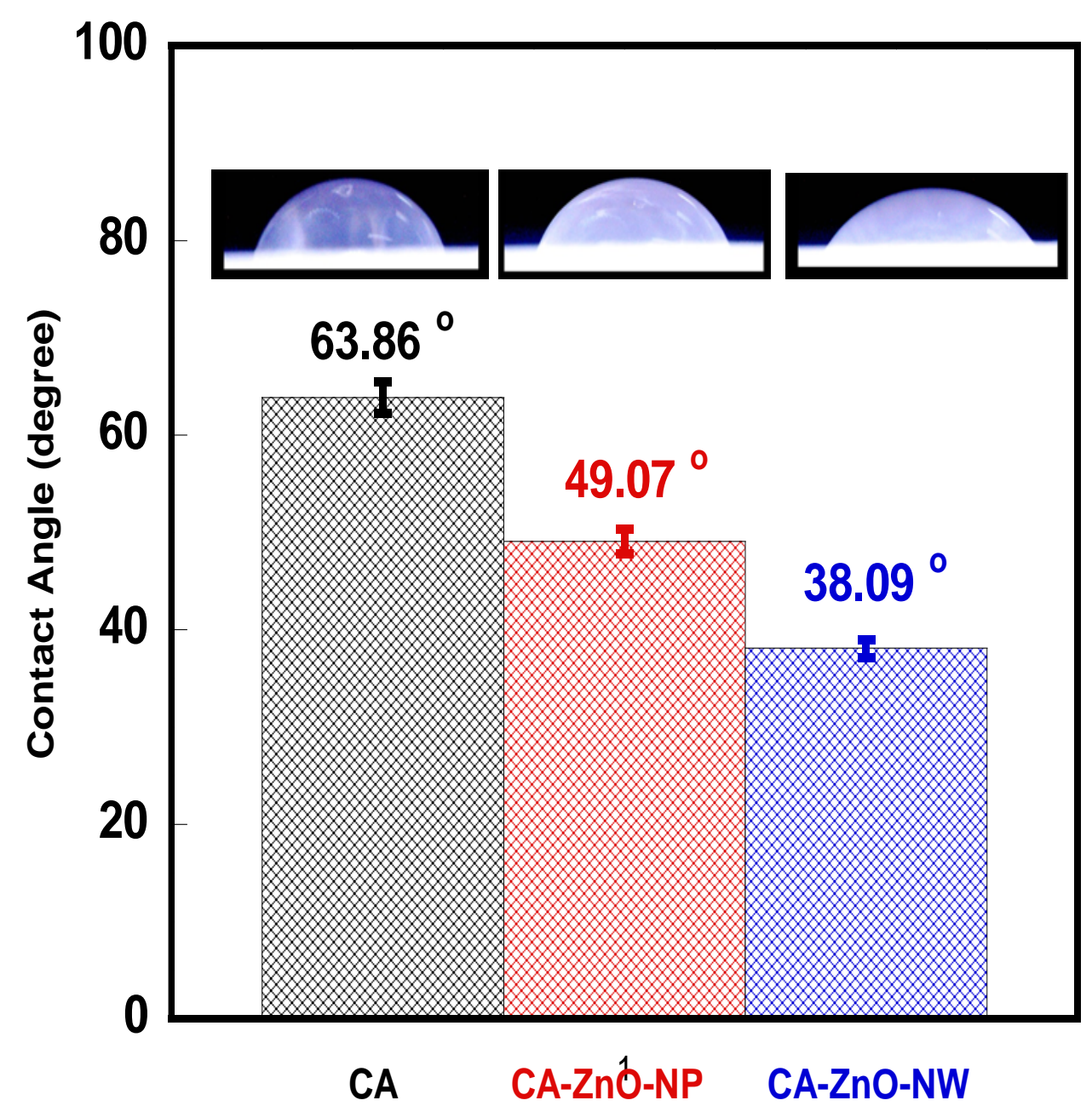

Figure 6. Contact angle measurements of the pristine CA membrane, the CA-ZnO-NP membrane, and the CA-ZnO-NW membrane. The insets show a photograph of a water droplet on each membrane. 
The results indicate hydrophilic surfaces for all membranes. The decrease in the contact angle (improvement of the hydrophilicity of the CA membranes) with the introduction of $\mathrm{ZnO}$ nanostructures into the CA matrix could have arisen due to the crystallinity and microstructural changes that occur during the growth of these nanostructures inside and on the boundaries of the CA porous network. Moreover, the surface of $\mathrm{ZnO}$ can be hydrophobic or hydrophilic depending on the $\mathrm{ZnO}$ /water interfacial interactions.

\subsection{Photocatalytic Activity}

Figure 7 presents the photocatalytic degradation of $\mathrm{MB}$ by the pristine $\mathrm{CA}, \mathrm{CA}$ ZnO-NP, and CA-ZnO-NW membranes after UV-light and sunlight irradiation. It can be observed in all samples that the absorbance intensity of the MB absorption peak (664 nm) decreased gradually for both UV-light and sunlight irradiation. The maximum degradation of MB under UV-light was observed in the CA-ZnO-NP membrane (about 60\%) after $2 \mathrm{~h}$ compared to the blank sample (Figure 7a). However, a more pronounced decrease (of more than $80 \%$ ) in the $\mathrm{MB}$ major absorption peak intensity was seen using the $\mathrm{CA}-\mathrm{ZnO}$ $\mathrm{NP}$ membrane in sunlight (Figure $7 \mathrm{~b}$ ). This suggests that CA-ZnO-NP membranes are a proper candidate for the photocatalytic degradation of $\mathrm{MB}$ compared to other membranes. Moreover, to optimize the experimental conditions for the best photocatalytic performance of the membranes, a systematic study was performed to find the optimum $\mathrm{ZnO}-\mathrm{NW}$, $\mathrm{ZnO}-\mathrm{NP}$, and $\mathrm{MB}$ concentrations for samples with excellent performance.

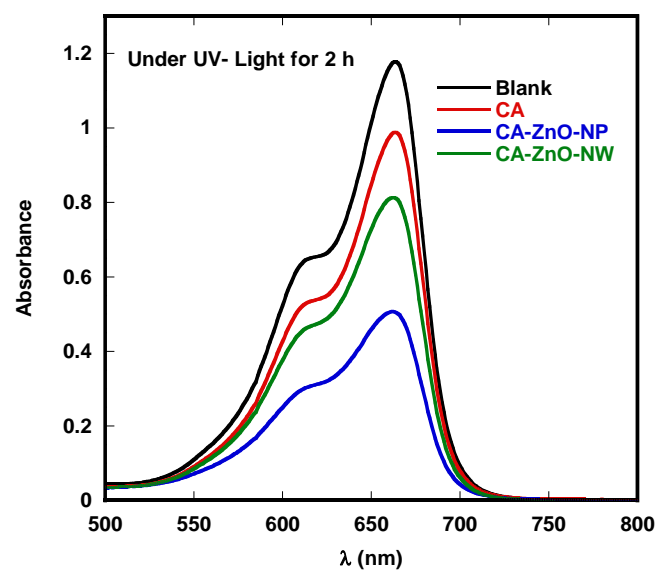

(a)

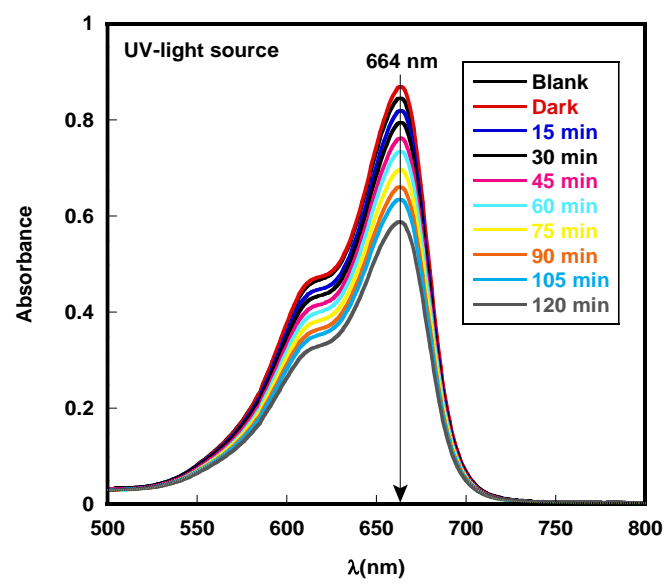

(c)

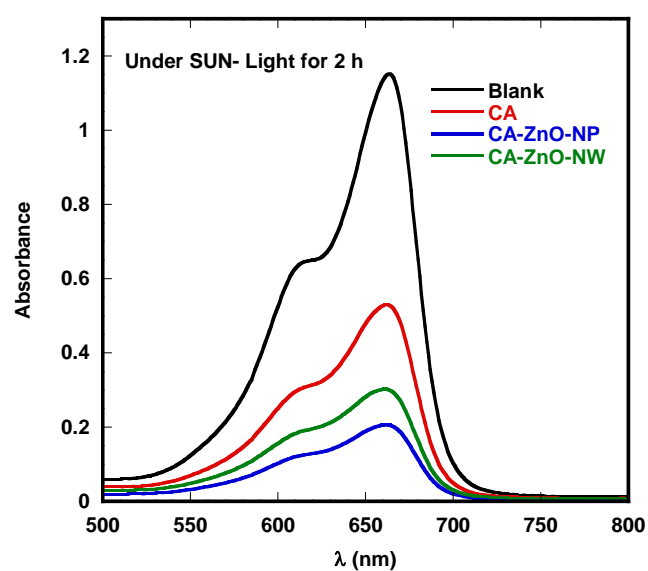

(b)

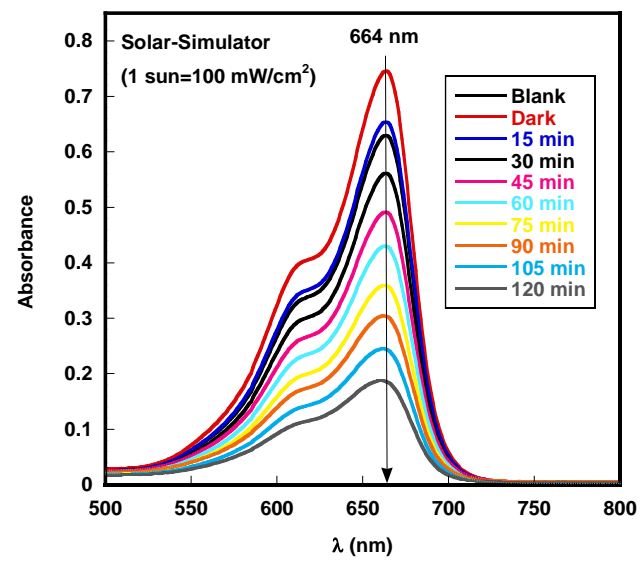

(d)

Figure 7. Photocatalytic degradation of $\mathrm{MB}$ by pristine CA, CA-ZnO-NP, and CA-ZnO-NW membranes, each after (a) UV-light irradiaton and (b) sunlight irradiation for $2 \mathrm{~h}$; MB degradation in the CA-ZnO-NP membrane under (c) UV-light irradiation and (d) sunlight irradiation every 15 min. 
Based on the obtained preliminary result, a systematical and detailed study was conducted for the CA-ZnO-NP membrane photocatalytic activity toward MB dye under both UV-light and sunlight irradiation.

The presented results revealed that the optimum results were obtained with samples of $20 \%$ weight. CA-ZnO-NP membranes were loaded in $5 \mathrm{mg} / \mathrm{L} \mathrm{MB}$ solution $(\mathrm{pH} \approx 7$ ) for $120 \mathrm{~min}$. The photocatalytic activity of the optimized samples was evaluated by observing the degradation of $\mathrm{MB}$ in the presence of the $\mathrm{CA}-\mathrm{ZnO}-\mathrm{NP}$ membrane under UV-light irradiation (Figure $7 \mathrm{c}$ ).

During the first 30 min (dark adsorption test), all samples showed a stable adsorptiondesorption equilibrium in $\mathrm{MB}$ solution. For comparison, we also studied the photocatalytic degradation of $\mathrm{MB}$ by direct photolysis, i.e., without using a catalyst under identical experimental conditions. A negligible degradation of $\mathrm{MB}(\sim 1 \%)$ over $2 \mathrm{~h}$ was observed, indicating that the properties of methylene blue are more stable. CA-ZnO-NP showed $\sim 30 \%$ of the MB dye reduction during the first $2 \mathrm{~h}$ of UV-light irradiation. The photocatalytic results under sunlight irradiation in the presence of CA-ZnO-NP showed a more rapid degradation of MB (about 75\%) (Figure 7d) compared to results obtained under UV-light irradiation. The results show that CA-ZnO-NP possesses the photocatalytic ability to degrade $\mathrm{MB}$ at different levels under both UV-light and sunlight irradiation.

The degradation of $\mathrm{MB}$ in the presence of $\mathrm{CA}-\mathrm{ZnO}-\mathrm{NP}$ membranes under UV-light and sunlight irradiation for an irradiation period of $120 \mathrm{~min}$ leads to the conversion of nitrogen and sulfur atoms in $\mathrm{MB}$ molecules into inorganic ions and gasses. As reported in Table 1, the reduction in TOC and the increase in ammonium $\left(\mathrm{NH}_{4}{ }^{+}\right)$, nitrate $\left(\mathrm{NO}_{3}{ }^{-1}\right)$, and sulfate $\left(\mathrm{SO}_{4}{ }^{-2}\right)$ concentrations confirmed the mineralization and decomposition of $\mathrm{MB}$ [41] and agree well with our degradation findings.

Table 1. The degradation products of MB in the presence of CA-ZnO-NP membranes under UV-light and sunlight irradiation for an irradiation period of $120 \mathrm{~min}$.

\begin{tabular}{cccc}
\hline Parameter & $\begin{array}{c}\text { Reading before } \\
\text { Degradation }\end{array}$ & $\begin{array}{c}\text { Reading after } \\
\text { Degradation with } \\
\text { CA/ZnO under } \\
\text { UV-Light Irradiation }\end{array}$ & $\begin{array}{c}\text { Reading after } \\
\text { Degradation with } \\
\text { CA/ZnO under } \\
\text { Sunlight Irradiation }\end{array}$ \\
\hline TOC (mg/L) & 2.1 & 0.76 & 0.43 \\
Ammonium (mg/L) & 0 & 0.4 & 0.6 \\
Nitrate (mg/L) & 0 & 1.1 & 4.1 \\
Sulfate (mg/L) & 0 & 7.8 & 9 \\
\hline
\end{tabular}

To gain a deep insight into the kinetic mechanism during the photocatalytic process, the $C / C_{0}$ versus degradation time plots are illustrated in Figure $8 \mathrm{a}$. The results indicate that the photodegradation process proceeded gradually with irradiation time, with a much steeper decrease for the CA-ZnO-NP membrane under sunlight compared to that for UV-light irradiation. The photodegradation of an organic dye generally occurs on the photocatalyst surface; the surface area becomes a significant issue in the photocatalysis process. The results clearly indicate that $\mathrm{MB}$ rapidly degraded in the presence of CA-ZnONP under sunlight irradiation, compared to under UV-light irradiation. 


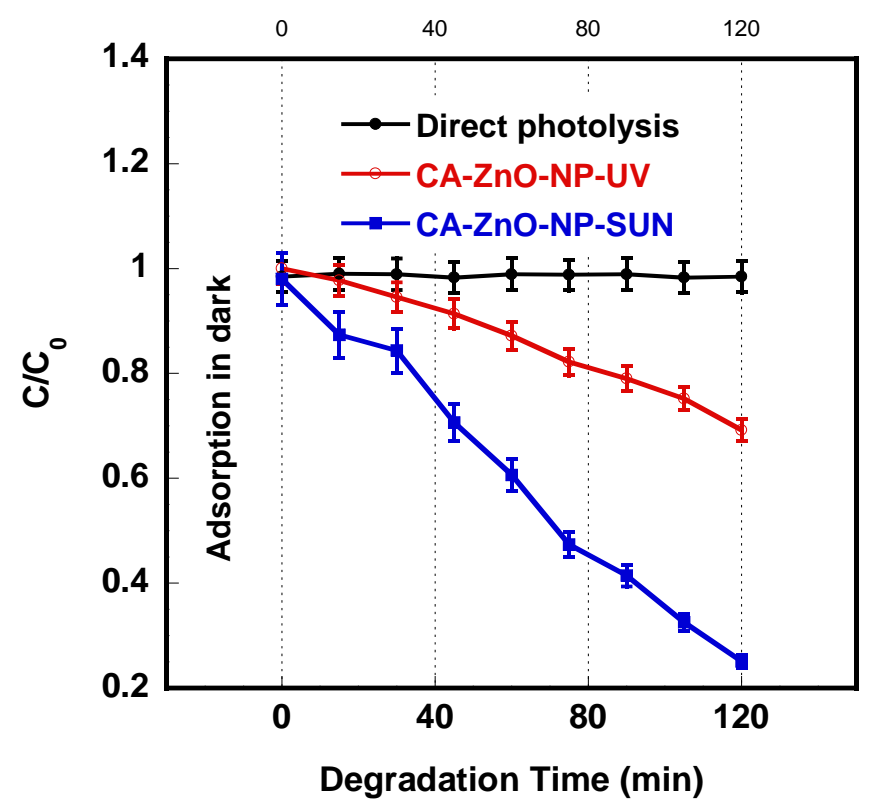

(a)

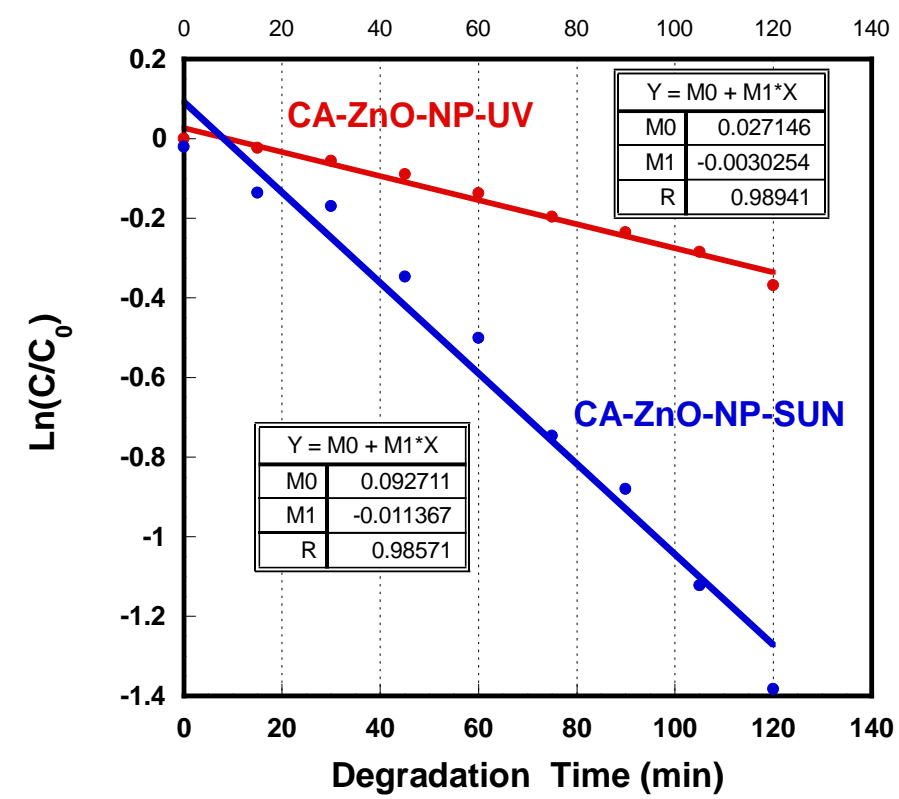

(b)

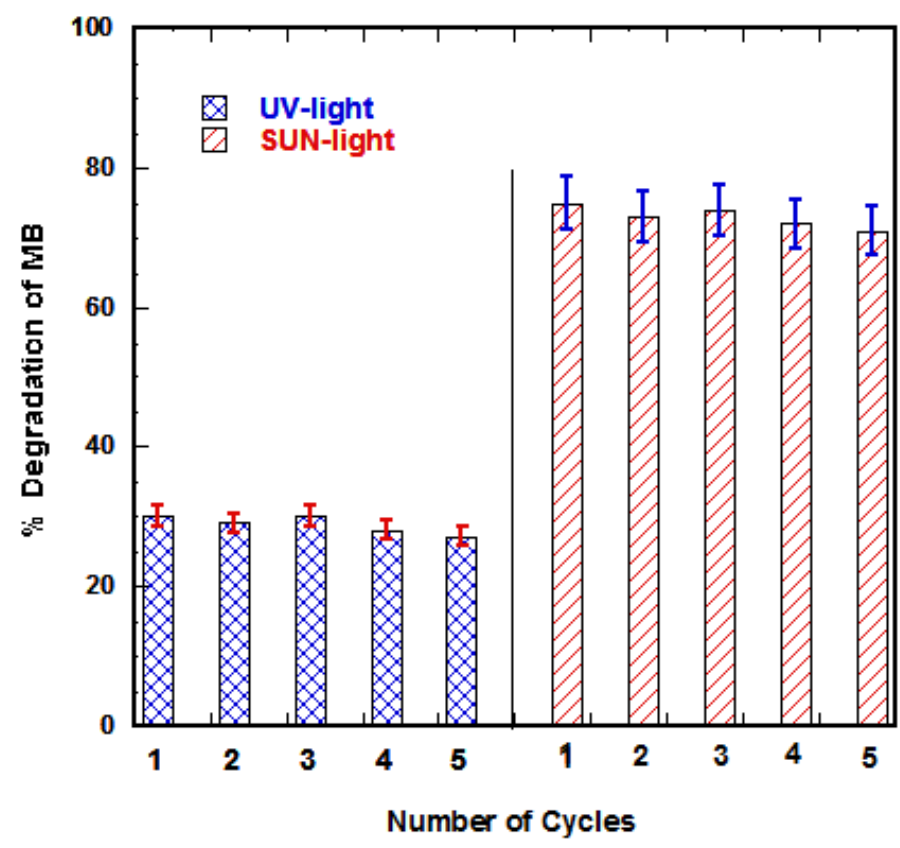

(c)

Figure 8. (a) Plots of $\mathrm{C} / \mathrm{C}_{0}$ vs. irradiation time for photocatalytic degradation of $\mathrm{MB}$ in the presence of $\mathrm{CA}-\mathrm{ZnO}-\mathrm{NP}$ membranes under UV-light and sunlight irradiation. (b) Plots of $\ln \left(C / C_{0}\right)$ vs. irradiation time for photocatalytic degradation of $\mathrm{MB}$ in the presence of CA-ZnO-NP membranes under UV-light and sunlight irradiation. (c) Cyclic runs showing the photocatalytic degradation of $\mathrm{MB}$ in the presence of $\mathrm{CA}-\mathrm{ZnO}-\mathrm{NP}$ membranes under UV-light and sunlight irradiation.

For better illustration of the degradation rates, the rate constants $(\mathrm{k})$ for the degradation of MB were calculated from the well known kinetic equation $\ln \left(C / C_{0}\right)=k \cdot t$ and plotted in Figure $8 \mathrm{~b}$, where the degradation rate constant $(\mathrm{k})$ was calculated from the slope of the line. For UV-light and sunlight irradiation, the rate constants were calculated to be 0.0030 and $0.0114 \mathrm{~min}^{-1}$, respectively. The CA-ZnO-NP membrane exhibited higher photocatalytic activity under sunlight (more than three times) than that under UV light. 
The linear plots illustrated in Figure 8b reveal that the degradation process of MB followed first order kinetics, which is in full agreement with [37] - A recently published study on ACF-ZnO-NR nanocomposites. This may be attributed to the high surface area contributed by $\mathrm{CA}$ fibers; high $\mathrm{ZnO}$ surface ratio; small $\mathrm{ZnO}-\mathrm{NP}$ size; and the wide spectrum of the sunlight, which increases the number of active sites on the membrane surface and thus leads to higher reactivity [42].

CA-ZnO-based nanocomposite photocatalytic activity, which may be attributed to the strong electronic interaction between $\mathrm{CA}$ and $\mathrm{ZnO}$, has been reported by Abdalkarim et al. [43]. Further findings from previous studies that investigated different polymeric $\mathrm{ZnO}$ nanocomposites with respect to $\mathrm{MB}$ degradation are summarized in Table 2.

Additionally, a photocatalytic mechanism for CA-ZnO-NP nanocomposite has been also reported. According to Huang et al. [44], during UV-light and sunlight irradiation, the photogenerated electron-hole pairs due to the $\mathrm{ZnO}-\mathrm{NP}$ light absorption migrate to the surface of $\mathrm{ZnO}$ and react with $\mathrm{O}_{2}$ and $\mathrm{H}_{2} \mathrm{O}$ absorbed on the surface of $\mathrm{ZnO}$ to generate $\mathrm{O}_{2}{ }^{-}$and $\mathrm{OH}^{-}$, which may contribute towards $\mathrm{MB}$ degradation through a direct oxidation process. We believe that, although CA-ZnO-NP nanocomposite possesses dual absorption of UV radiation and visible light from sunlight for enhanced photocatalytic activity, the generation of reactive radical species in each electromagnetic radiation is quite different and requires further systematic investigation. Therefore, this may also lead to the application of sunlight radiation alone in the wastewater treatment industry, since sunlight is a readily available type of light with both UV and visible light components.

Table 2. Comparison of MB Dye degradation in different studies.

\begin{tabular}{|c|c|c|c|c|c|c|}
\hline $\begin{array}{l}\text { Photo-Catalyst } \\
\text { Composition }\end{array}$ & $\begin{array}{c}\text { MB } \\
\text { Concentration }\end{array}$ & $\begin{array}{l}\text { Irradiation Time } \\
(\text { min) }\end{array}$ & $\begin{array}{l}\text { Rate Constant } \\
\qquad \min ^{-1}\end{array}$ & $\begin{array}{c}\% \\
\text { Degradation }\end{array}$ & $\begin{array}{l}\text { Type of } \\
\text { Irradiation }\end{array}$ & Reference \\
\hline \multicolumn{7}{|l|}{ Polyaniline/Zinc oxide } \\
\hline $1: 1$ & $50(\mathrm{mg} / \mathrm{L})$ & 120 & 0.006 & 52.0 & \multirow{3}{*}{ Visible light } & \multirow{3}{*}[45]{} \\
\hline $1: 2$ & $50(\mathrm{mg} / \mathrm{L})$ & 120 & 0.01944 & 90 & & \\
\hline $1: 3$ & $50(\mathrm{mg} / \mathrm{L})$ & 120 & 0.00724 & 58.9 & & \\
\hline \multicolumn{6}{|l|}{ Polyaniline/Zinc oxide } & \multirow[b]{2}{*}[46]{} \\
\hline PANI/0.5 wt $\%$ ZnO & $10(\mathrm{mg} / \mathrm{L})$ & 180 & NS & 76 & Visible light & \\
\hline \multirow{2}{*}{$\begin{array}{l}\text { Polyaniline/Zinc oxide } \\
\text { (catalyst concentration: } \\
0.4 \mathrm{mg} / \mathrm{mL} \text { ) }\end{array}$} & $1 \times 10^{-5} \mathrm{M}$ & 300 & 0.011 & 79 & UV light & \multirow[b]{2}{*}[47]{} \\
\hline & $1 \times 10^{-5} \mathrm{M}$ & 300 & 0.02405 & 97 & Sunlight & \\
\hline \multicolumn{6}{|l|}{ Polyimide/ZnO } & \multirow{5}{*}[48]{} \\
\hline $0.2 \mathrm{M} \mathrm{ZnO}$ & $5(\mathrm{mg} / \mathrm{L})$ & 150 & 0.0166 & 92 & \multirow{4}{*}{ UV light } & \\
\hline $0.5 \mathrm{M} \mathrm{ZnO}$ & $5(\mathrm{mg} / \mathrm{L})$ & 150 & 0.0283 & 98 & & \\
\hline $1.0 \mathrm{M} \mathrm{ZnO}$ & $5(\mathrm{mg} / \mathrm{L})$ & 150 & 0.0216 & 96 & & \\
\hline $2.0 \mathrm{M} \mathrm{ZnO}$ & $5(\mathrm{mg} / \mathrm{L})$ & 150 & 0.010 & 75 & & \\
\hline \multicolumn{6}{|l|}{$\begin{array}{l}\text { Poly (methyl } \\
\text { methacrylate) } \\
\text { (PMMA)/ZnO }\end{array}$} & \multirow{4}{*}{ [29] } \\
\hline Powders & & 240 & 0.041 & 60 & \multirow{3}{*}{ UV light } & \\
\hline composite film & & 240 & 0.026 & 40 & & \\
\hline flat film & & 240 & 0.017 & 30 & & \\
\hline $\begin{array}{c}\text { Cellulose/ } \mathrm{ZnO} \\
35 \mathrm{mg} \text { of nanopowders }\end{array}$ & $3.25(\mathrm{~g} / \mathrm{L})$ & 300 & $0.1174 \mathrm{~h}^{-1}$ & 79 & UV light & [49] \\
\hline Cellulose acetate/ZnO & & 120 & 0.0030 & 30 & UV light & \\
\hline Cellulose acetate/ZnO & & 120 & 0.0114 & 75 & Sunlight & This work \\
\hline
\end{tabular}

NS: not studied.

The reproducibility of the CA-ZnO-NP membrane with respect to the photodegradation of MB under UV-light and sunlight irradiation is shown in Figure 8c. The photodegradation was monitored for five cycles, each for $120 \mathrm{~min}$. After each cycle, the membrane was taken off from the MB solution, washed thoroughly with water, and then transferred to a fresh MB solution. The figure shows no significant change in the removal efficiency or 
photocatalytic degradation during the five consecutive cycles under UV-light and sunlight irradiation.

In addition, $\mathrm{Zn}$ ion leaching from the membranes was evaluated at the end of each cycle after the photocatalytic process; the concentration for each membrane was determined quantitatively using Shimadzu (AA-6200) atomic absorption flame emission spectroscopy. The results showed a total $\mathrm{Zn}$ leaching of only $0.38 \%$ (UV-light irradiation) and $0.36 \%$ (sunlight irradiation) of total membrane $\mathrm{Zn}$ content after five cycles of operation. This indicates the excellent durability, recyclability, and reproducibility of the CA-ZnO-NP membranes with respect to the photodegradation of MB.

\section{Conclusions}

In this work, the polymeric CA-ZnO nanocomposite membranes were easily fabricated using the phase inversion method and sono-hydrothermal synthesis technique. $\mathrm{ZnO}$ nanostructures (nanoparticles and nanowires) were applied to fabricate a CA-based composite membrane to enhance their performance by investigating the MB photocatalytic degradation in aqueous solutions. Compared to pristine the $\mathrm{CA}$ membrane, the CA-ZnO-NP and CA-ZnO-NW membranes exhibited enhanced photocatalytic activity and degradation of MB. The results obtained via XRD and SEM demonstrate a clear modification of their structural and morphological properties due to impregnation of $\mathrm{ZnO}$ nanostructures. The optimum concentrations, size, and shape of the impregnated $\mathrm{ZnO}$ nanostructures (nanoparticles, nanowires, nanoflowers, etc.) are crucial for membrane performance, since the presence of large nanoclusters and agglomerations may create structural defects which may have a negative impact on the membrane quality and performance. Moreover, the photocatalyst could also be conveniently recovered and used for subsequent runs at sustained proficiencies. Besides the degradation of organic dye compounds, the inhibition of microbial growth by the $\mathrm{ZnO}$ nanostructures parallel to UV-light and sunlight irradiation could be potential topics for future investigation.

Author Contributions: M.A.A.-D. and B.A.A. conceptualized and designed the study, shared the experimentation data analysis and manuscript preparation and editing. S.A.A.-R. performed the experiments and participated in data analysis and manuscript writing. All authors have read and agreed to the published version of the manuscript.

Funding: This research was funded by Jordan University of Science and Technology, Jordan (grant\# 157/2020).

Institutional Review Board Statement: Not applicable.

Informed Consent Statement: Not applicable.

Data Availability Statement: The data presented in this study are available on request from the corresponding author.

Acknowledgments: The authors would like to acknowledge the deanship of research at Jordan University of Science and Technology, Jordan, for funding support grant \# 157/2020.

Conflicts of Interest: The authors declare no conflict of interest.

\section{References}

1. Russo, V.; Masiello, D.; Trifuoggi, M.; Di Serio, M.; Tesser, R. Design of an adsorption column for methylene blue abatement over silica: From batch to continuous modeling. Chem. Eng. J. 2016, 302, 287-295. [CrossRef]

2. He, X.; Male, K.B.; Nesterenko, P.; Brabazon, D.; Paull, B.; Luong, J. Adsorption and Desorption of Methylene Blue on Porous Carbon Monoliths and Nanocrystalline Cellulose. ACS Appl. Mater. Interfaces 2013, 5, 8796-8804. [CrossRef] [PubMed]

3. Yu, D.; Wang, Y.; Wu, M.; Zhang, L.; Wang, L.; Ni, H. Surface functionalization of cellulose with hyperbranched polyamide for efficient adsorption of organic dyes and heavy metals. J. Clean. Prod. 2019, 232, 774-783. [CrossRef]

4. Yang, T.; Yu, D.; Wang, D.; Yang, T.; Li, Z.; Wu, M.; Petru, M.; Crittenden, J. Accelerating Fe(III)/Fe(II) cycle via Fe(II) substitution for enhancing Fenton-like performance of Fe-MOFs. Appl. Catal. B: Environ. 2021, 286, 119859. [CrossRef]

5. Yu, D.; Wang, L.; Yang, T.; Yang, G.; Wang, D.; Ni, H.; Wu, M. Tuning Lewis acidity of iron-based metal-organic frameworks for enhanced catalytic ozonation. Chem. Eng. J. 2021, 404, 127075. [CrossRef] 
6. Yu, D.; Li, L.; Wu, M.; Crittenden, J.C. Enhanced photocatalytic ozonation of organic pollutants using an iron-based metal-organic framework. Appl. Catal. B Environ. 2019, 251, 66-75. [CrossRef]

7. Nuengmatcha, P.; Chanthai, S.; Mahachai, R.; Oh, W.-C. Sonocatalytic performance of ZnO/graphene/TiO2 nanocomposite for degradation of dye pollutants (methylene blue, texbrite BAC-L, texbrite BBU-L and texbrite NFW-L) under ultrasonic irradiation. Dye. Pigment. 2016, 134, 487-497. [CrossRef]

8. Chen, B.; Zhou, S.; Zhang, L.; You, T.; Xu, F. Adsorption of Heavy Metals by Graphene Oxide/Cellulose Hydrogel Prepared from $\mathrm{NaOH} /$ Urea Aqueous Solution. Materials 2016, 9, 582. [CrossRef]

9. Carpenter, A.W.; De Lannoy, C.-F.; Wiesner, M.R. Cellulose Nanomaterials in Water Treatment Technologies. Environ. Sci. Technol. 2015, 49, 5277-5287. [CrossRef]

10. Kim, J.; Van der Bruggen, B. The use of nanoparticles in polymeric and ceramic membrane structures: Review of manufacturing procedures and performance improvement for water treatment. Environ. Pollut. 2010, 158, 2335-2349. [CrossRef]

11. Bobade, V.; Eshtiag, N. Heavy metals removal from wastewater by adsorption process: A review. In Proceedings of the Asia Pacific Confederation of Chemical Engineering Congress 2015 (APCChE 2015), Melbourne, Australia, 27 September-1 October 2015; pp. 312-317.

12. Saber-Samandari, S.; Gazi, M. Removal of Mercury (II) from Aqueous Solution using Chitosan-graft-Polyacrylamide Semi-IPN Hydrogels. Sep. Sci. Technol. 2013, 48, 1382-1390. [CrossRef]

13. Pillay, K.; Cukrowska, E.; Coville, N. Multi-walled carbon nanotubes as adsorbents for the removal of parts per billion levels of hexavalent chromium from aqueous solution. J. Hazard. Mater. 2009, 166, 1067-1075. [CrossRef]

14. Abad, S.N.K.; Mozammel, M.; Moghaddam, J.; Mostafaei, A.; Chmielus, M. Highly porous, flexible and robust cellulose acetate $/ \mathrm{Au} / \mathrm{ZnO}$ as a hybrid photocatalyst. Appl. Surf. Sci. 2020, 526, 146237. [CrossRef]

15. El-Noss, M.; Isawi, H.; Shawky, H.A.; Gomaa, M.; Abdel-Mottaleb, M. Improvement of cellulose acetate forward osmosis membrane performance using zinc oxide nanoparticles. Desalin. Water Treat. 2020, 193, 19-33. [CrossRef]

16. Rajesha, B.; Vishaka, V.H.; Balakrishna, R.G.; Padaki, M.; Nazri, N. Effective composite membranes of cellulose acetate for removal of benzophenone-3. J. Water Process. Eng. 2019, 30, 100419. [CrossRef]

17. Wen, Y.; Yuan, J.; Ma, X.; Wang, S.; Liu, Y. Polymeric nanocomposite membranes for water treatment: A review. Environ. Chem. Lett. 2019, 17, 1539-1551. [CrossRef]

18. Al-Wafi, R.; Ahmed, M.; Mansour, S. Tuning the synthetic conditions of graphene oxide/magnetite/ hydroxyapatite/cellulose acetate nanofibrous membranes for removing $\mathrm{Cr}(\mathrm{VI})$, Se(IV) and methylene blue from aqueous solutions. J. Water Process. Eng. 2020, 38, 101543. [CrossRef]

19. Durthi, C.P.; Rajulapati, S.B.; Palliparambi, A.A.; Kola, A.K.; Sonawane, S.H. Studies on removal of arsenic using cellulose acetate-zinc oxide nanoparticle mixed matrix membrane. Int. Nano Lett. 2018, 8, 201-211. [CrossRef]

20. Serbanescu, O.S.; Pandele, A.M.; Miculescu, F.; Voicu, S.I. Synthesis and Characterization of Cellulose Acetate Membranes with Self-Indicating Properties by Changing the Membrane Surface Color for Separation of Gd(III). Coatings 2020, 10, 468. [CrossRef]

21. ZabihiSahebi, A.; Koushkbaghi, S.; Pishnamazi, M.; Askari, A.; Khosravi, R.; Irani, M. Synthesis of cellulose acetate/chitosan/ SWCNT $/ \mathrm{Fe}_{3} \mathrm{O}_{4} / \mathrm{TiO}_{2}$ composite nanofibers for the removal of $\mathrm{Cr}(\mathrm{VI})$, As(V), Methylene blue and Congo red from aqueous solutions. Int. J. Biol. Macromol. 2019, 140, 1296-1304. [CrossRef]

22. Marrez, D.A.; Abdelhamid, A.E.; Darwesh, O.M. Eco-friendly cellulose acetate green synthesized silver nano-composite as antibacterial packaging system for food safety. Food Packag. Shelf Life 2019, 20, 100302. [CrossRef]

23. Dodero, A.; Alloisio, M.; Vicini, S.; Castellano, M. Preparation of composite alginate-based electrospun membranes loaded with ZnO nanoparticles. Carbohydr. Polym. 2020, 227, 115371. [CrossRef] [PubMed]

24. Liang, S.; Xiao, K.; Mo, Y.; Huang, X. A novel ZnO nanoparticle blended polyvinylidene fluoride membrane for anti-irreversible fouling. J. Membr. Sci. 2012, 394-395, 184-192. [CrossRef]

25. Mahlangu, O.T.; Nackaerts, R.; Mamba, B.; Verliefde, A.R.D. Development of hydrophilic GO-ZnO/PES membranes for treatment of pharmaceutical wastewater. Water Sci. Technol. 2017, 76, 501-514. [CrossRef] [PubMed]

26. Pintilie, S.C.; Tiron, L.G.; Lazar, A.L.; Vlad, M.; Birsan, I.G.; Balta, S. The Influence of ZnO/TiO2 Nanohybrid Blending on the Ultrafiltration Polysulfone Membranes. Mater. Plast. 2018, 55, 54-62. [CrossRef]

27. Anitha, S.; Brabu, B.; Thiruvadigal, D.J.; Gopalakrishnan, C.; Natarajan, T. Optical, bactericidal and water repellent properties of electrospun nano-composite membranes of cellulose acetate and ZnO. Carbohydr. Polym. 2013, 97, 856-863. [CrossRef]

28. Sheikh, M.; Pazirofteh, M.; Dehghani, M.; Asghari, M.; Rezakazemi, M.; Valderrama, C.; Cortina, J.-L. Application of ZnO nanostructures in ceramic and polymeric membranes for water and wastewater technologies: A review. Chem. Eng. J. 2020, 391, 123475. [CrossRef]

29. Di Mauro, A.; Cantarella, M.; Nicotra, G.; Pellegrino, G.; Gulino, A.; Brundo, M.V.; Privitera, V.; Impellizzeri, G. Novel synthesis of ZnO/PMMA nanocomposites for photocatalytic applications. Sci. Rep. 2017, 7, 40895. [CrossRef]

30. Thondavada, N.; Chokkareddy, R.; Naidu, N.V.; Redhi, G.G. Environmental Science and Engineering Applications of Polymer and Nanocellulose-Based Nanocomposites. In Composites for Environmental Engineering; Wiley: Hoboken, NJ, USA, 2019 ; pp. 135-178.

31. Zhou, H.; Touny, A.; Bhaduri, S.B. Fabrication of novel PLA/CDHA bionanocomposite fibers for tissue engineering applications via electrospinning. J. Mater. Sci. Mater. Med. 2011, 22, 1183-1193. [CrossRef]

32. Moore, T.T.; Mahajan, R.; Vu, D.Q.; Koros, W.J. Hybrid membrane materials comprising organic polymers with rigid dispersed phases. AIChE J. 2004, 50, 311-321. [CrossRef] 
33. Rabajczyk, A.; Zielecka, M.; Cygańczuk, K.; Pastuszka, Ł.; Jurecki, L. Nanometals-Containing Polymeric Membranes for Purification Processes. Materials 2021, 14, 513. [CrossRef]

34. Zhao, S.; Yan, W.; Shi, M.; Wang, Z.; Wang, J.; Wang, S. Improving permeability and antifouling performance of polyethersulfone ultrafiltration membrane by incorporation of ZnO-DMF dispersion containing nano-ZnO and polyvinylpyrrolidone. J. Membr. Sci. 2015, 478, 105-116. [CrossRef]

35. Fu, F.; Li, L.; Liu, L.; Cai, J.; Zhang, Y.; Zhou, J.; Zhang, L. Construction of Cellulose Based ZnO Nanocomposite Films with Antibacterial Properties through One-Step Coagulation. ACS Appl. Mater. Interfaces 2015, 7, 2597-2606. [CrossRef] [PubMed]

36. Cheng, J.; Zhan, C.; Wu, J.; Cui, Z.; Si, J.; Wang, Q.; Peng, X.; Turng, L.-S. Highly Efficient Removal of Methylene Blue Dye from an Aqueous Solution Using Cellulose Acetate Nanofibrous Membranes Modified by Polydopamine. ACS Omega 2020, 5, 5389-5400. [CrossRef] [PubMed]

37. Albiss, B.; Abu-Dalo, M. Photocatalytic Degradation of Methylene Blue Using Zinc Oxide Nanorods Grown on Activated Carbon Fibers. Sustainability 2021, 13, 4729. [CrossRef]

38. Wahab, H.; Salama, A.; El-Saeid, A.; Nur, O.; Willander, M.; Battisha, I. Optical, structural and morphological studies of (ZnO) nano-rod thin films for biosensor applications using sol gel technique. Res. Phys. 2013, 3, 46-51. [CrossRef]

39. Valente, A.; Burrows, H.; Polishchuk, A.; Domingues, C.; Borges, O.; Eusébio, M.E.S.; Maria, T.; Lobo, V.; Monkman, A. Permeation of sodium dodecyl sulfate through polyaniline-modified cellulose acetate membranes. Polymer 2005, 46, 5918-5928. [CrossRef]

40. Chatterjee, P.K.; Conrad, C.M. Thermogravimetric analysis of cellulose. J. Polym. Sci. Part A-1 Polym. Chem. 1968, 6, 3217-3233. [CrossRef]

41. Houas, A.; Lachheb, H.; Ksibi, M.; Elaloui, E.; Guillard, C.; Herrmann, J.M. Photocatalytic degradation pathway of methylene blue in water. Appl. Catal. B Environ. 2001, 31, 145-157. [CrossRef]

42. Ibhadon, A.O.; Fitzpatrick, P. Heterogeneous Photocatalysis: Recent Advances and Applications. Catalysts 2013, 3, 189-218. [CrossRef]

43. Abdalkarim, S.Y.H.; Yu, H.-Y.; Wang, C.; Yang, L.; Guan, Y.; Huang, L.; Yao, J. Sheet-like Cellulose Nanocrystal-ZnO Nanohybrids as Multifunctional Reinforcing Agents in Biopolyester Composite Nanofibers with Ultrahigh UV-Shielding and Antibacterial Performances. ACS Appl. Bio Mater. 2018, 1, 714-727. [CrossRef]

44. Huang, N.; Shu, J.; Wang, Z.; Chen, M.; Ren, C.; Zhang, W. One-step pyrolytic synthesis of ZnO nanorods with enhanced photocatalytic activity and high photostability under visible light and UV light irradiation. J. Alloys Compd. 2015, 648, 919-929. [CrossRef]

45. Qin, R.; Hao, L.; Liu, Y.; Zhang, Y. Polyaniline-ZnO Hybrid Nanocomposites with Enhanced Photocatalytic and Electrochemical Performance. ChemistrySelect 2018, 3, 6286-6293. [CrossRef]

46. Ameen, S.; Akhtar, M.S.; Kim, Y.S.; Yang, O.-B.; Shin, H.-S. An effective nanocomposite of polyaniline and ZnO: Preparation, characterizations, and its photocatalytic activity. Colloid Polym. Sci. 2011, 289, 415-421. [CrossRef]

47. Eskizeybek, V.; Sarı, F.; Gülce, H.; Gülce, A.; Avc1, A. Preparation of the new polyaniline/ZnO nanocomposite and its photocatalytic activity for degradation of methylene blue and malachite green dyes under UV and natural sun lights irradiations. Appl. Catal. B Environ. 2012, 119-120, 197-206. [CrossRef]

48. Ding, Q.; Miao, Y.-E.; Liu, T. Morphology and Photocatalytic Property of Hierarchical Polyimide/ZnO Fibers Prepared via a Direct Ion-exchange Process. ACS Appl. Mater. Interfaces 2013, 5, 5617-5622. [CrossRef]

49. Lefatshe, K.; Muiva, C.M.; Kebaabetswe, L.P. Extraction of nanocellulose and in-situ casting of ZnO/cellulose nanocomposite with enhanced photocatalytic and antibacterial activity. Carbohydr. Polym. 2017, 164, 301-308. [CrossRef] 